\title{
Distribution and Ecological Characteristics of Native Iris Odesanensis in Mt. Naeyon
}

\author{
Young-Hee Ahn, Sang-Hyun Lee, Sung-Je Lee and Ki-Ho Kang* \\ Department of Applied Plant Science, Chung-Ang University, Ansung 456-756, Korea \\ Key-chungsan Botanical Garden, Pohang 791-922, Korea \\ (Manuscript received 25 August, 2006; accepted 15 December, 2006)
}

\begin{abstract}
Iris odesanensis Y.N. Lee is one kind of species among 54 endangered plant species designated by the Ministry of Environment in Korea. It is very rare native plant throughout the country. Therefore, this study was conducted to investigate the native Iris odesanensis in Mt. Naeyon for their distribution and ecological characteristics. They were mostly distributed mid-slope of the mountain from $443 \mathrm{~m}$ to $498 \mathrm{~m}$ altitude. They were located lower part of valley and provided enough humid condition. They had proper light and humidity conditions as they faced south south west, south south east, and south. They were also located at the places deciduous woody plants were distributed for proper light conditions for spring blooming. Iris flowered to use light at the period before the trees thickly covered with foliage. However this unfavorable light condition caused low percentage as $7.04 \%$ of blooming individuals in this study. In herbaceous, Viola chaerophylloides (Regel) W. Becker, Carex siderosticta Hance, Erythronium japonicum Decne., Oxalis obtriangulata Max., Hepatica asiatica Nakai, Lilium tsingtauense Gilg et cetera were appeared well. We propose that proper pruning of upper branches of the deciduous trees is needed for suitable light condition of management of native
\end{abstract} sites.

Key Words: Iris odesanensis, Endangered plant, Management, Native site

\section{Introduction}

Iris odesanensis Y.N. Lee, called as No-Ran-Mu$\mathrm{Ni}$-Buts-Kot, is very rare plant which is only restricted in Korea. Its height is about $20 \mathrm{~cm}$ and its rhizomes spread to horizontally.

Leaf is sword-shape and $12-35 \mathrm{~cm}$ long and $12 \mathrm{~mm}$ wide. It blooms in April to May and its size is about $3.5 \mathrm{~cm}$. Petal is white and yellow stripe is on it's middle part ${ }^{b}$. It is one kind of species among 54 endangered plant species designated by the Ministry of Environment in Korea ${ }^{2)}$. The Korea Forest Service designated it as a rare and endangered plant and protect it thoroughly ${ }^{3)}$. It is very rare native plant throughout the country. Iris species are monocotyledonous and perennial herbaceous plants belonging to Iridaceae ${ }^{4)}$. There are about 300 species of upright, rhizomatous or bulbous, sometimes fleshy-rooted

Corresponding Author : Young-Hee Ahn, Department of Applied Plant Science, Chung-Ang University, Ansung 456-756, Korea

Phone: $+82-31-670-3041$

E-mail: ecoplant@cau.ac.kr perennials found in a wide range habitats from the temperate zone to the subarctic zone in the Northern hemisphere $^{5)}$. Because flowers and leaves of Iris species are very beautiful, these plants are generally cultivated as flowering plants in order to sell their flowers, or replant in pots or flower gardens. Roots or rhizomes of Iris species are thick and has lots of medicinal ingredients. Its roots or rhizomes are called as Doo-Si-Cho(豆豉草), its medicinal name, and which is known for its effect of anti-inflammation and digestive promoter ${ }^{6)}$.

About 10 species including Iris odesanensis have been found in Korea. However their definite distribution and ecological characteristics of native site is not known at all. There is no information of native site in Korea, so it is not possible to protect and even restoration of Iris odesanensis. It grows natively in Korea and is discovered in lofty mountains in Kangwon-do and Palgong-mountain in Kyungsangbuk-do. Mt. Naeyon is an eminent mountain and located at Kyungsangpook-do province ${ }^{\prime)}$. Recently native site of 
Iris odesanensis was discovered there. Also there is no knowledge of ecological characteristics of Iris odesanensis. Therefore it is not possible to utilize it as a useful plant resource because of impracticability to artificial propagation and culture, ${ }^{8,9}$.

There are more than 4000 native plant species in Korea. However, there are few precedent that various native plants were developed as plant resources ${ }^{10-13)}$. This was due to there is not enough study of native plants in wild situation. There is little scientific report of nation wide distribution of native plants and their native sites ${ }^{14)}$. A succeeded to culture native Iris odesanensis based on the result of ecological research. However there is few results of ecological research which enable to develop native plants to valuable resources. Therefore, this study was conducted to investigate the native Iris odesanensis in Mt. Naeyon for their distribution and ecological characteristics. This may be useful to basic data as protect and restoration of native sites and culture it as a plant resource.

\section{Material and Methods}

This study was carried out in the area of $\mathrm{Mt}$. Naeyon, Pohang city, Kyungsangpook-do province, native site of Iris odesanensis. It was carried out from April to October 2005. Investigation plots were established quadrate on the herb layer including Iris odesanensis. Areas of the quadrates were $5 \times 10 \mathrm{~m} \sim$ $3 \times 8 \mathrm{~m}$ which represent the ecological characteristics of native sites. dominance, sociability, height of vegetation, and covering pecentage of vegetation of emerging plants were investigated ${ }^{15)}$. Exact location points were decided by GPS (global position system, GPS-V PLUS). Also altitude, degree of slope, compass direction of slope, light condition, soil condition, and so on was investigated. Especially lighting condition was described as percentage comparing the intensity of illumination of native and other sites. Vegetation of native sites were investigated by phytosociological method of Braun-Blanquet ${ }^{16}$. The communities on native sites were classified through phytosocialogical table work $^{17)}$.

\section{Results and Discussion}

Mt. Naeyon is located in southern part of Kyungsangpook-do province and last part of Taebaek mountain range. Its altitude is $930 \mathrm{~m}$. It is reported as it has rich flora. The climate of the native site is typical temperate climate. Area, of native sites of Iris odesanensis were ranged from $36 \mathrm{~m}^{2}$ to $200 \mathrm{~m}^{2}$ and number of the sites were 8 . Locations of the native sites were indicated roughly to protect them indiscretion people. Total 476 individuals were identified. From total 476 individuals, 56 individuals, $7.04 \%$ of all, were reproductive as flowering or seeding(Table 1). Detailed site description will not be mentioned for protection of native sites. They were mostly distributed mid-slope of the mountain from $443 \mathrm{~m}$ to $498 \mathrm{~m}$ altitude(Fig. 1). They were located lower part of valley and provided enough humid condition. They had proper light and humidity conditions as they faced south south west, south south east, and south(Fig. 2). They were located on the slope of 35 to 43 degrees(Fig. 3). Soil pH of the native sites was slightly acidic as the average 5.03 . Soil hardness was the average $0.31 \mathrm{~kg} / \mathrm{cm}^{2}$. About $80.84 \%$ of soil was gravel. Soil humidity was slightly dry as average $14.85 \%$. About $18.67 \%$ of sun light was reached to the sites and average illuminance was 3.04 Klux. Native sites were semi-shaded because of tree layer such as Acer mono Max., Ulmus davidiana var. ja

Table 1. The habitat area and number of the individual plant Iris odesanensis

\begin{tabular}{|c|c|c|c|c|}
\hline $\begin{array}{l}\text { No. of } \\
\text { quadrate }\end{array}$ & Latitude(N) & Longitude(E) & Area of habitats $\left(\mathrm{cm}^{2}\right)$ & $\begin{array}{l}\% \text { of flowering individuals (No. of flowering } \\
\text { individuals / No. of whole individuals) }\end{array}$ \\
\hline 1 & $\mathrm{~N} 36^{\circ} 14^{\prime} 0^{\prime \prime}$ & $\mathrm{E} 129^{\circ} 15^{\circ} 0^{\prime \prime}$ & 16 & $13.16(5 / 38)$ \\
\hline 2 & $\mathrm{~N} 36^{\circ} 14^{\prime} 0^{\prime \prime}$ & E $129^{\circ} 15^{\prime} 0^{\prime \prime}$ & 14 & $4.29(3 / 70)$ \\
\hline 3 & $N 36^{\circ} 14^{\prime} 0^{\prime \prime}$ & $\mathrm{E} 129^{\circ} 15^{\circ} 0^{\prime \prime}$ & 16 & $3.06(3 / 98)$ \\
\hline 4 & $\mathrm{~N} 36^{\circ} 14^{\prime} 0^{\prime \prime}$ & E $129^{\circ} 15^{\prime} 0^{\prime \prime}$ & 12 & $12.5(2 / 16)$ \\
\hline 5 & $N 36^{\circ} 13^{\prime} 0^{\prime \prime}$ & E $129^{\circ} 15^{\prime} 0^{\prime \prime}$ & 50 & $2.02(4 / 198)$ \\
\hline 6 & $\mathrm{~N} 36^{\circ} 13^{\prime} 0^{\prime \prime}$ & E $129^{\circ} 15^{\prime} 0^{\prime \prime}$ & 14 & $8.33(2 / 24)$ \\
\hline 7 & $N 36^{\circ} 13^{\prime} 0^{\prime \prime}$ & E $129^{\circ} 15^{\prime} 0^{\prime \prime}$ & 10 & $5.26(1 / 19)$ \\
\hline 8 & $\mathrm{~N} 36^{\circ} 13^{\prime} 0^{\prime \prime}$ & E $129^{\circ} 15^{\prime} 0^{\prime \prime}$ & 10 & $7.69(1 / 13)$ \\
\hline
\end{tabular}


Distribution and ecological characteristics of native Iris odesanensis in Mt. Naeyon

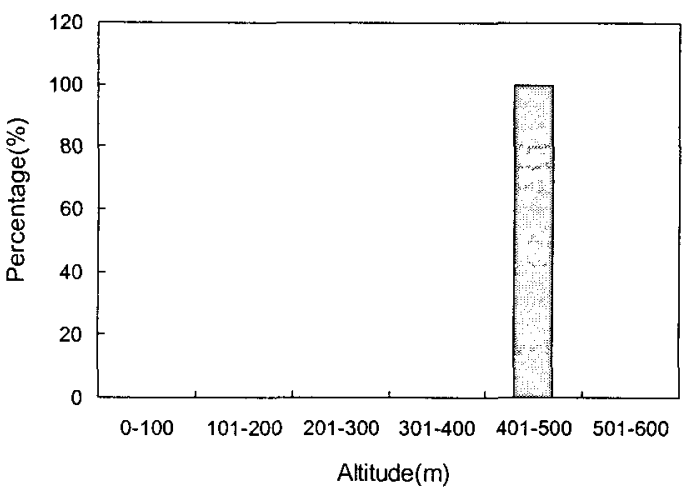

Fig. 1. Altitude of Iris odosanensis habitat.

N

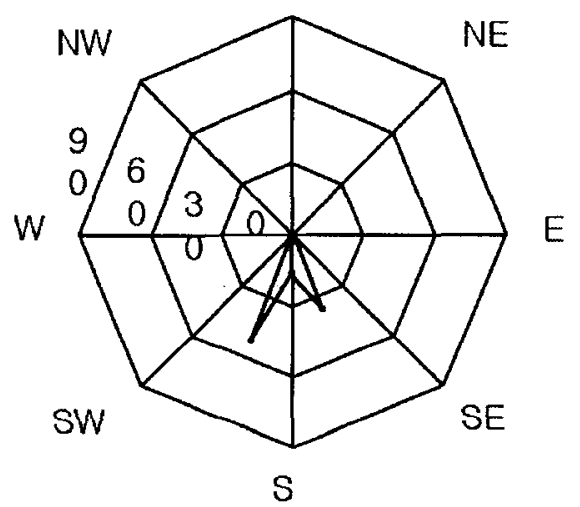

Fig. 2. Direction of Iris odosanensis habitat.

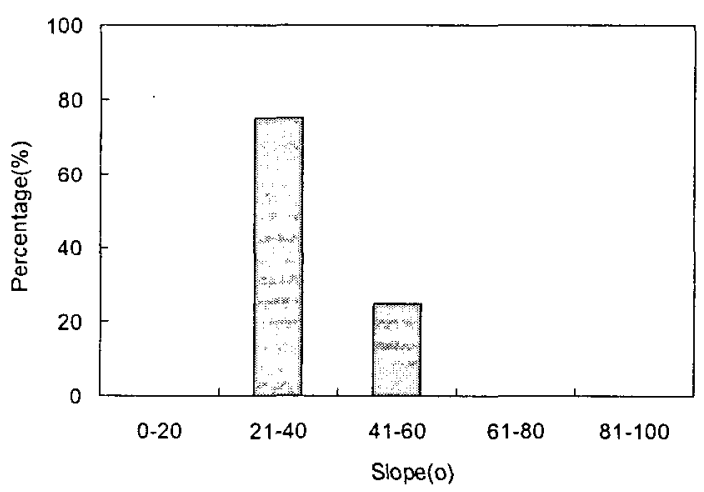

Fig. 3. Slope gradient of Iris odosanensis habitat.

ponica Nak., Quercus serrata Thunb., Berchemia berchemiaefolia (Mak.) Koidz., et cetera and sub-tall tree layer such as Styrax obassia S.et Z., Staphylea bumalda DC., Lindera obtusiloba Bl. and so on were grown near by. Woody plants such as Styrax obassia S. et Z., Staphylea bumalda DC., Stephanandra incisa Zabel., Lonicera subsessilis Rehder et cetera were fre- quently observed. Those were mostly observed at shaded and humid valleys. They were also located at the places deciduous woody plants were distributed for proper light conditions for spring blooming. Iris flowered to use light at the period before the trees thickly covered with foliage ${ }^{14)}$. However this unfavorable light condition caused low percentage as $7.04 \%$ of blooming individuals in this study. We propose that proper pruning of upper branches of the deciduous trees is needed for suitable light condition of management of native sites ${ }^{8}$. In herbaceous, Viola chaerophylloides (Regel) W. Becker, Carex siderosticta Hance, Erythronium japonicum Decne., Oxalis obtriangulata Max., Hepatica asiatica Nakai, Lilium tsingtauense Gilg et cetera were appeared well(Fig. 4). Such herbaceous plants prefer aerial humidity and relatively short, therefore Iris probably predominant than these plant in the ecological competition ${ }^{18)}$. Average height of herbaceous plants was $0.3 \mathrm{~m}$, the percentage of vegetation cover was $61.25 \%$, and average appearing species was 11 . Especially in the native sites, typ-

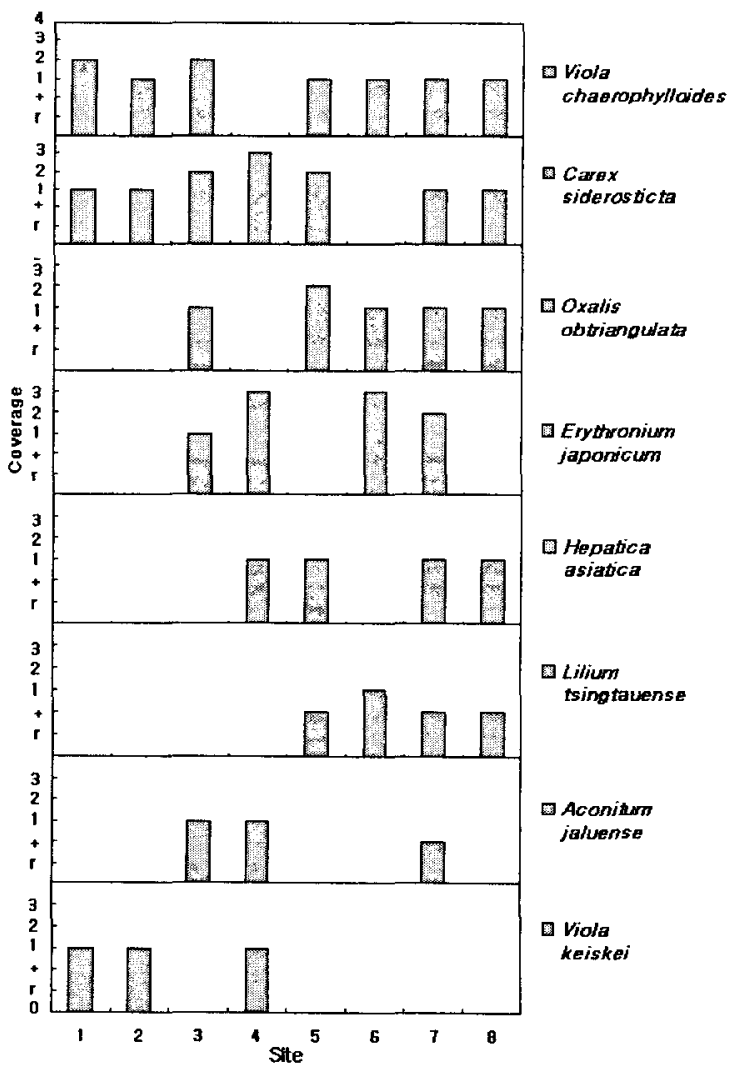

Fig. 4. Coverage of each layer at Iris odesanensis habitat. 
Young-Hee Ahn, Sang-Hyun Lee, Sung-Je Lee and Ki-Ho Kang

Table 2. Phytosociological table on the Iris odesanensis habitat in Mt. Naeyon

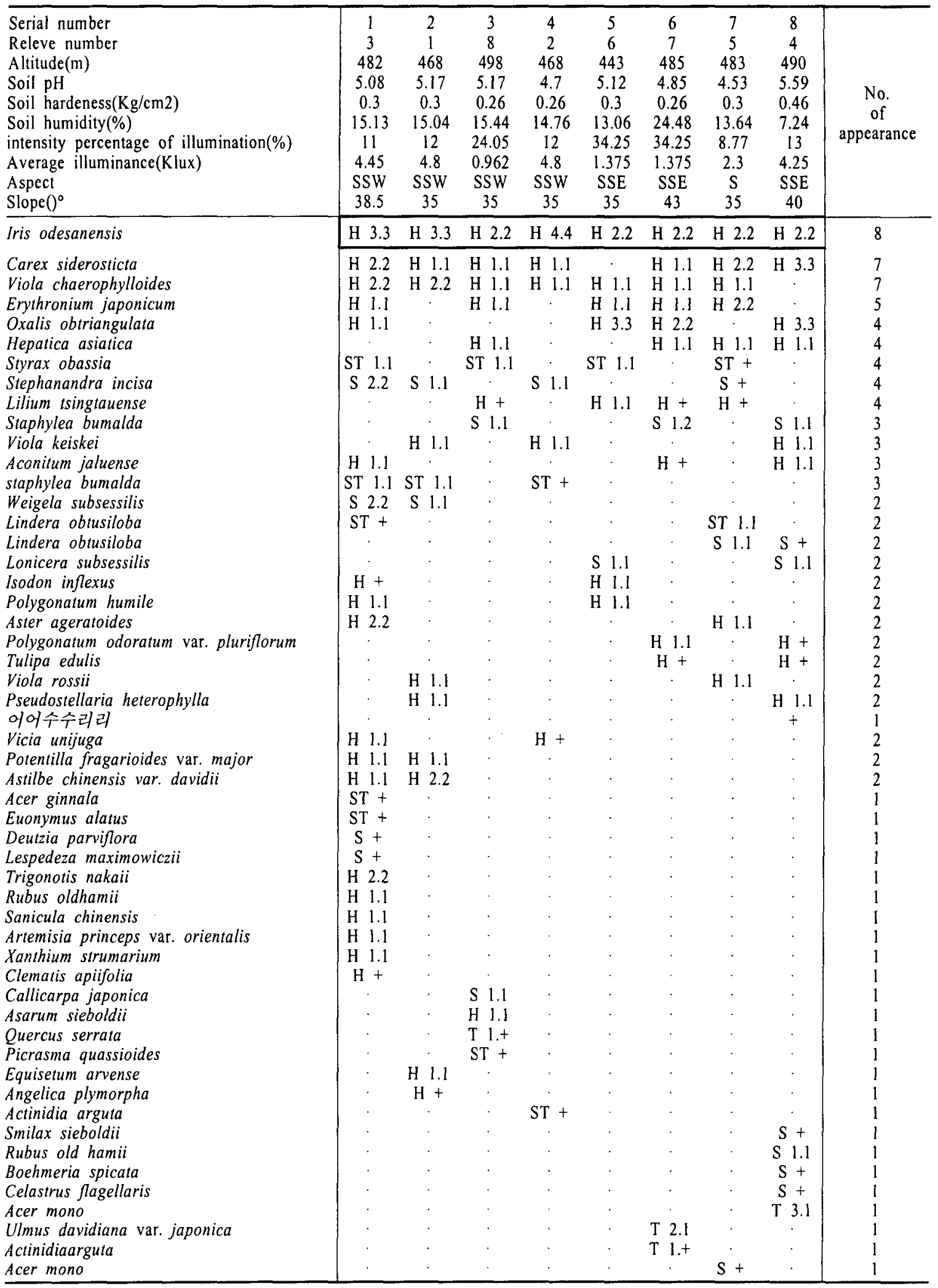


ical short plants such as Viola chaerophylloides (Regel) W. Becker, Viola keiskei Miq., Viola rossii Hemsl., Viola grypoceras A. Gray in genera Viola were appeared. In south south west faced native site, proper light and enough humid conditioned place, Stephanandra incisa Zabel., Deutzia parviflora Bunge., Lespedeza maximowiczii Schneid., Astilbe chinensis var. davidii Fr., Vicia unijuga A. Br., Trigonotis nakaii Hara et cetera were appeared. However in south south east or south faced sites, relatively more light condition places, Smilax sieboldii Miq., Rubus oldhamii Miq., Polygonatum odoratum var. pluriflorum Ohwi., Tulipa edulis Bak. et cetera were appeared. Especially vines such as Actinidia arguta Planch., Rubus oldhamii Miq., Clematis apiifolia A. P. DC. et cetera and strong Leguminosae or Chrisanthemums should be removed(Table 2). These plants could make worse of light condition of native sites and take advantages in ecological competition to Iris ${ }^{9}$. For conservation of Iris native sites and continue of individual number, environment should be maintained properly and reasonable removal of competitors may be needed ${ }^{19}$.

\section{Reference}

1) Lee, Y. N., 2002, Flora of Korea, Kyohaksa publishing $\mathrm{Co}$, Seoul, 953pp.

2) Ministry of Environment in Korea, 2005, http:// www.me.go.kr/.

3) Korea forest service, 2005, http://www.me.go.kr/.

4) Ahn, Y. H., 2005, Analysis of genetic relationship of native Iris species plants using RAPD, Jour. of the Environmental Science, 14(3), 265269.

5) Shibata, K, 1998, A cyclopedia of useful plants and plant products, Hokuryukan Co., Tokyo, pp. 514-519.

6) Chung, B. S. and M. K. Shin, 2002, Encyclopedia of Pharmacognosy. Youngrimsa, Seoul, pp.194-197.

7) Ahn, Y. H. and K. Y. Choi, 2002, Ecological characteristics and distribution of Korean native Rhapontica uniflora at habitats, Kor. J. Hort. Sci. \& Technol., 20, 126-133.
8) Ahn, Y. H., K. H. Chung, K. Y. Choi and D. S. Park, 2001, Ecological characteristics and distribution of plant resources of Pyrus and Malus sp. in Jindong vally, Gwangwon province, Plant Res, 4(3), 130-139.

9) Ahn, Y. H., K. H. Chung and H. S. Park, 2003, Vegetation and flora of Hibiscus hamabo inhabited naturally in Soan Island, Jour. of the Environmental Science, 12(11), 1181-1187.

10) Ahn, Y. H., J. H. Sul and K. H. Cho, 1998, Effect of preservation period, light, temperature, and priming on the seed germination of Lysimachia mauritiana, Kor. J. Env. Eco., 12(1), 9-13.

11) Ahn, Y. H., S. H. Kim, C. H. Lee and S. T. Lee, 1999, Palynotaxonomic study of the genus Hemerocallis in Korea, J. Kor. Soc. Hort. Sci., 40(4), 505-510.

12) Ahn, Y. H., S. H. Yeau, N. S. Lee and S. T. Lee, 1999, Studies on characteristics of Adonis amurensis native to South Korea, Kor. J. Env. Eco., 13(3), 203-208.

13) Cho, K. H. and Y. H. Ahn, 2000, Effect of sucrose and supplementary substances on the germination ecology and the seedling growth of native Bletilla striata, Kor. J. Env. Eco., 14(3), 205-211.

14) Ahn, Y. H., 2005, Ecological characteristics and distribution of native Scrophularia takesimensis in Ulleung-do Island, Jour. of the Environmental Science, 14(12), 1087-1092.

15) Ecology research group, 1967, Manual of ecological research, Asakura publishing Co., Tokyo, pp.238-246.

16) Braun-Blanquet, J., 1964, Pflazensoziologie, Grundzude der Vegetationskunde, 3rd ed. Springer, New York, $85 \mathrm{pp}$.

17) Ishitsuka, K. O., 1982, Distribution of plant community and environment, Asakura publishing Co., Tokyo, pp.329-340.

18) Wilson, J. B. and G. W. Lee, 1989, Infilteration invasion, Functionnal Ecology, pp.379-382.

19) Matsuo T. N., 1989, Collected data of plant genetic resources, Kodansha Scientific Co., Tokyo, pp.4-27. 